\title{
Critical Studies on Security
}

\section{Commensurability of research methods in critical security studies}

\section{Can E. Mutlu \& Mark B. Salter}

To cite this article: Can E. Mutlu \& Mark B. Salter (2014) Commensurability of research methods in critical security studies, Critical Studies on Security, 2:3, 353-355, DOI:

$10.1080 / 21624887.2014 .982392$

To link to this article: https://doi.org/10.1080/21624887.2014.982392

曲 Published online: 17 Dec 2014.

6 Submit your article to this journal $\sqrt{6}$

Цlll Article views: 215

View Crossmark data \lceil 


\title{
Commensurability of research methods in critical security studies
}

\author{
Can E. Mutlu ${ }^{\mathrm{a} *}$ and Mark B. Salter ${ }^{\mathrm{b}}$ \\ ${ }^{a}$ Department of International Relations, Bilkent University, Ankara, Turkey; ${ }^{b}$ School of Political \\ Studies, University of Ottawa, Ottawa, Canada
}

\section{Introduction}

In the past few years, the critical security studies field has witnessed the emergence of a debate on the role of methods. ${ }^{1}$ Along with our edited volume on Research Methods in Critical Security Studies: An Introduction, there have been a number of exciting contributions (Shepherd 2013; Aradau and Huysmans 2013; Aradau et al. forthcoming) that further developed this focus on methods in critical security studies. Whereas our edited volume looked at the issue of research design, with a particular focus on questions surrounding sufficient proof, critical position and coherence, others have either focused on ontological and epistemological issues surrounding the meaning of critical methods, and the use of methods as 'devices and acts that disrupt social and political worlds' (Aradau and Huysmans 2013, 3), or ventured into a territory where theories and methods were discussed in an intertwined fashion (Shepherd 2013).

In this forum, we invited our contributors to build on this debate by asking them to discuss the question(s) of cumulative knowledge in a multi-method field such as critical security studies, and what that means for broader discussions of methods and methodology in the field. In particular, we pressed the contributors to discuss the concept of commensurability in critical security studies methods.

Critical security studies have exogenous and endogenous factors contributing to both theoretical and methodological developments that disrupt, discipline and transform the field in numerous and simultaneous ways. It is very difficult to identify that boundary where the field and the other fields begin. This is not a disadvantage. Critical security scholars are wanderers, not to say pirates. We travel into far away disciplines and bring back concepts, ideas or tools that we believe that explain the social and the political in reflexive ways. Emerging contributions to scholarship in critical security studies that touch on emotions, feminisms, science and technology, and popular culture, among others all make theoretical contributions that originate from debates in other disciplines. A complex social requires non-disciplinary thinking that is attuned to mess and is itself disorganized. Just as Searlian speech act theory informs the kind of discourse analysis often used in studying Securitization Theory or the Bourdieusian field analysis informs practice-driven approaches, exogenous theories and methods get incorporated into critical security studies in different ways that either build on existing knowledge claims, or dramatically transform, or disrupt them; wandering across disciplinary boundaries result in the cross-pollination of disciplinary fields.

When we asked, 'how do we do what we do?' (Salter and Mutlu 2013, 1), our goal was neither to discipline nor disrupt the field. What we were, and continue to be,

*Corresponding author. Email: canmutlu@bilkent.edu.tr 
interested in, were the reflexive attitudes that are at the core of the discipline and how that attitude fosters new methods for critical, or reflexive, research. Method in our use of the term does not symbolize a desire for 'doing' science or positivism. It is a frank discussion on ways of doing research. Our use of the term is closer to the ancient Greek origins of the term methodos, meaning the way, or journey, towards knowledge. We aspire to start a discussion about the journey of research, asking researchers to be reflexive about their way. While the question of methods and research design has exogenous connections, trying to (re)claim the domain of the empirical back from the positivist hegemony has proven to be a challenge for both critical International Relations (IR) and critical security studies. For us, that question represents an attempt to demonstrate to the rest of IR field, that critical security studies has many methods, or ways, of doing research that are both systematic and rigorous. Asking that question with a positive and non-defensive tone also creates a set of endogenous questions regarding the already existing methods, or ways, of doing 'critical' security. Some of the questions we have identified, along with the contributors to this forum and elsewhere, are: What's the role of methods in critical research? Can methods be critical? What makes certain methods critical, and others not? What are the conditions of possibility for critical methods? Our goal is to find new ways to talk about methods, to liberate methods from the positivistic scientific standard of commensurability and yet still be able to put different research projects in conversation with one another.

Seven interventions sketch out the stakes of this debate about methods. Burgess tackles the question of commensurability directly by invoking its philosophical grounding, suggesting that there is an implicit tension in the question: 'Critique, by its very character, inserts a sabot in the wheels of the social scientific commensurability machinery' (Burgess, this issue). Kurowska and Mireanu observe that for critical security studies to retain its inherently critical character, it must engage a spirit of 'agonistic pluralism among internally consistent approaches' (Kurowska and Mireanu, this issue). They foreground the individual experience of going into and remaining open to the field, which would radically destabilize the idea of a method-as-tool, in order to 'make sense'. Johnson sets out her experience doing ethnographic work in migration studies and sets out some of the stakes for ethnography in IR, arguing that our research and our interventions must be 'complex and mobilized, drawn across and between contexts and scales' (Johnson, this issue). Grove derives the same imperative to be 'attentive to how the whole world can be studied rather than picking and choosing the processes that conform to a desired research agenda' (this issue), although he highlights the constitutive role of material strata in those complex worlds. Lisle demonstrates the utility of this kind of approach by surveying the achievements of critical scholarship over the past 20 years, highlighting the innovations in forms of analysis that are precisely not hostage to mainstream restrictions on scientific tests of commensurability. Frowd sets out the general grounds for these questions of commensurability and criticality. Balzacq provides triangulation as a particularly useful strategy, grounded in his own work on securitization theory.

One of the commonalities in these diverse contributions is that our promptness to reflect on the question of commensurability of critical security studies was soundly rejected across the interventions, but rejected in particularly interesting ways. An essential component of the critical project is to be self-reflexive, to ask serious questions of the politics of the legitimation of knowledge claims. These questions can never be answered for once and for all, but must be answered in temporary, contingent and complex ways, reflecting our multiple and contradictory understandings of ourselves and our worlds. 


\section{Note}

1. Claudia Aradau, Jef Huysmans, Andrew Neal, and Nadine Voelkner must be recognized for establishing the 'International Collaboratory in Critical Methods in Security Studies' (ICCM) with an ESRC grant (RES-810-021-0072), and starting this debate back in 2010. In March 2011, we were able to contribute to this dialogue on the other side of the Atlantic with a workshop organized in Ottawa, Canada, with the support of Social Sciences and Research Council of Canada and the University of Ottawa, which resulted in our edited volume.

\section{Notes on contributors}

Can E. Mutlu is assistant professor of International Studies at Bilkent University, having received his doctorate at the University of Ottawa. He is a co-editor, with Mark Salter of Research Methods in Critical Security Studies (Routledge 2013).

Mark B. Salter is full professor at the School of Political Studies, University of Ottawa. He is a coeditor, with Can Mutlu of Research Methods in Critical Security Studies (Routledge 2013).

\section{References}

Aradau, C., and J. Huysmans. 2013. "Critical Methods in International Relations: The Politics of Techniques, Devices and Acts." European Journal of International Relations 1-24. OnlineFirst version. doi:http://dx.doi.org/10.1177/1354066112474479

Aradau, C., J. Huysmans, A. Neal, and N. Voelkner, eds. forthcoming. Critical Security Methods: New Frameworks of Analysis. Abingdon: Routledge.

Salter, M. B., and C. E. Mutlu, eds. 2013. Research Methods in Critical Security Studies: An Introduction. Abingdon: Routledge.

Shepherd, L., ed. 2013. Critical Approaches to Security: An Introduction to Theories and Methods. New York: Routledge. 